\title{
Materials Taking a Lesson from Nature
}

\author{
Liangfei Tian ${ }^{\text {ab }}$, Emmanuel Croisier ${ }^{\mathrm{a}}$, and Holger Frauenrath ${ }^{\star \mathrm{a}}$
}

\begin{abstract}
Structural biomaterials with their often extraordinary properties and versatile functions are typically constructed from very limited sets of building blocks and types of supramolecular interactions. In this review we discuss how, inspired by nature's design principles for protein-based materials, oligopeptide-modified polymers can be used as a versatile toolbox to program nanostructure and hierarchical structure formation in synthetic materials.
\end{abstract}

Keywords: Biomaterials · Hierarchical structure formation · Oligopeptides · Supramolecular self-assembly

\section{Introduction}

Structural biomaterials often exhibit extraordinary mechanical properties, which is remarkable considering that they are typically prepared under benign physiological conditions. ${ }^{[1,2]}$ Even more notable is the fact that structural biomaterials with tailored and vastly different properties and functions are derived and constructed from very limited sets of building blocks. ${ }^{[3]}$ Among the most versatile materials in this regard are proteins that probably constitute the largest class of biomaterials. The mechanical properties of proteins and protein-rich materials can be broadly tailored, e.g. from exhibiting high toughness and mechanical strength (silk), ${ }^{[4,5]}$ over good elastic response (ligaments), ${ }^{[6,7]}$ to excellent damping properties (cartilage). ${ }^{[8,9]}$ And yet, all the constituent proteins are obtained from the same tool box of natural amino acids and assembled with a restricted set of non-covalent interactions, including mostly Coulomb forces, hydrogen-bonding, Van der Waals interactions and the solvophobic effect. ${ }^{*}$ Correspondence: Prof. Dr. H. Frauenrath
Tel.: +41 216937399

E-mail: holger.frauenrath@epfl.ch

a Laboratory of Macromolecular \& Organic Materials

École Polytechnique Fédérale de Lausanne

EPFL - STI - IMX - LMOM

Building MXG, Room 037, Station 12

$\mathrm{CH}-1015$ Lausanne

bepartment of Materials

Eidgenössische Technische Hochschule Zürich

Wolfgang-Pauli-Strasse 10

$\mathrm{CH}-8093$ Zürich
Nature achieves this versatile tailoring of biomaterials' properties by carefully controlling the molecular structure of the constituting biopolymers and the resulting geometries of supramolecular interactions between their chemical building blocks (peptides) on several length scales and levels of the structural hierarchy. ${ }^{[10,11]}$ The information to form higher structures is encoded into their molecular structure and they are, thus, designed to self-organize into precursor materials. The latter are then converted into the final materials with the aid of processing procedures, e.g. spinning of silk protein, guiding the system to find the desired structure among energetically similar alternatives.

Inspired by nature's design principles, hierarchically structured synthetic polymers have attracted strong interest in the materials community. ${ }^{[12-14]}$ Although huge progress has been made in the field of synthetic polymer chemistry over the past decades, the tools at hand to exert a control of polymer structure comparable to biological systems are still limited in scope. This is why novel and better polymer materials will probably be obtained as polymer chemists continue to learn from nature's examples. This review article aims to demonstrate how one can try take a page from nature's playbook and utilize oligopeptidemodified polymers to prepare molecular nanostructures or hierarchically structured materials.

\section{Lessons from Silk Materials}

Silk materials may be regarded as one inspiration for the materials to be reviewed here, due to their impressive mechanical properties. ${ }^{[4,5,15-19]}$ Hence, the mechanical properties, as well as the molecular and nanostructures of silk will be discussed in detail in this section. The mechanical properties of silk materials are extraordinary in terms of strength and toughness, in particular, the properties of spider dragline silk, which exhibits an extensibility of about $30 \%$ and a strength comparable to high-tensile steel and Kevlar. As a consequence, its toughness exceeds that of Kevlar or steel (Table 1), despite the fact that this material is produced under physiological conditions.[4,15,18-20] Moreover, silk materials can be tailored according to their actual functions. Hence, the mechanical properties of silk materials may vary broadly, from the sticky and adhesive pyriform silk (for attaching spider webs to substrates) over the highly elastic flagelliform silk (for capture spirals) to the tough and strong major ampullate silk (for spider dragline and web scaffolds). ${ }^{[15]}$

Silk materials are complex multimaterials, which are composed of proteins and other components, such as glycoproteins and lipids. ${ }^{[15,16,19,21-23]}$ The major protein components, such as Major Ampullate Spidroins 1 and 2 in the case of spider dragline silk, have a macromolecular ar-

Table 1. Mechanical properties of spider dragline silk and man-made materials ${ }^{[15]}$

\begin{tabular}{|l|c|c|c|}
\hline \multicolumn{1}{|c|}{ Material } & $\begin{array}{c}\text { Strength } \\
\left(\sigma_{\max } / \mathrm{GPa}\right)\end{array}$ & $\begin{array}{c}\text { Extensibility } \\
\left(\varepsilon_{\max }\right)\end{array}$ & $\begin{array}{c}\text { Toughness } \\
\left(\mathrm{MJm}^{-3}\right)\end{array}$ \\
\hline Dragline silk (A. diadematus $)$ & 1.1 & 0.27 & 160 \\
\hline Nylon & 0.95 & 0.18 & 80 \\
\hline Kevlar 49 & 3.6 & 0.027 & 50 \\
\hline High-tensile steel & 1.5 & 0.008 & 6 \\
\hline
\end{tabular}




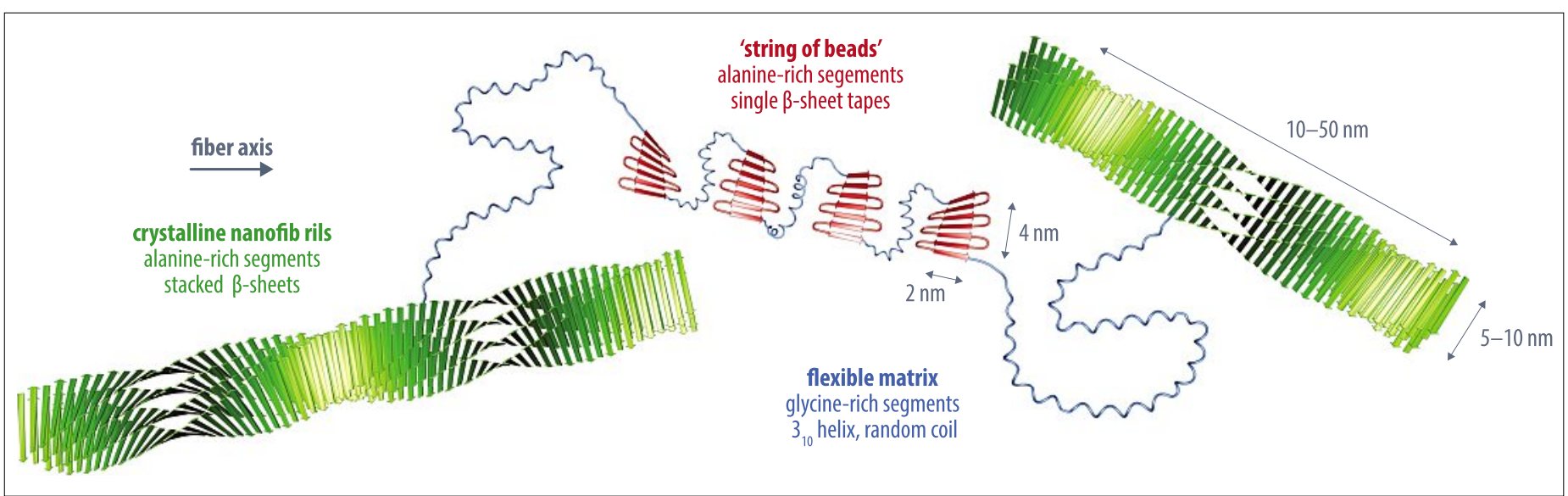

Fig. 1. Schematic illustration of the coexisting nanoscopic features of spider dragline silk (only a segment of the multiblock macromolecule shown, and loops/coils attached to all other $\beta$-strands omitted for clarity).

chitecture composed of an alternating sequence of well-defined L-alanine-rich (hard) and glycine-rich (soft) segments folded and self-organized carefully during the spinning process. ${ }^{[16,24-31]}$ The hard segments are constituted from hydrophobic L-alanine-rich segments, either in the form of GAGA- and GGA-flanked AAAAAA sequences (spider dragline silk) ${ }^{[32-34]}$ or GAGAGA sequences (spider silks and silkworm silk). ${ }^{[5,15]}$ A highly ordered fraction of these $\beta$-sheet-forming segments crystallizes into nanoscopic fibrillar crystallites with cross- $\beta$-sheet signature in $\mathrm{X}$-ray diffractograms that serve as physical cross-links (Fig. 1). These crystallites may be regarded as nanofibrillar fillers and are mainly responsible for the high strength of spider dragline silk. ${ }^{[4,32-34]}$ At the same time, a second less well-ordered fraction, also called intramolecular $\beta$-sheet structures and composed of about $50 \%$ of the L-alanine-rich segments, forms a covalently connected 'string of beads' of short single $\beta$-sheet tapes. They consist of about seven folds of 6-10 amino acid residues each. ${ }^{[33,35-38]}$ The successive unfolding of these $\beta$-sheet tapes by breaking of hydrogen-bonds upon mechanical load, associated with possible transverse (stickslip) $\beta$-strand motion dissipates energy and is believed to be responsible for the remarkably high toughness of silk materials. ${ }^{[37,39-41]}$ The two types of L-alanine-rich hard domains are then embedded into a more or less amorphous matrix of soft glycine-rich segments that adopt $3_{10}$-helical, random coil, or $\beta$-strand structures, which provides further elasticity and extensibility to the material. ${ }^{[34,42]}$

\section{Self-Assembly of Amyloid Proteins and Oligopeptide- Modified Polymers}

The self-assembly of the silk protein into different nanoscopic $\beta$-sheet struc-

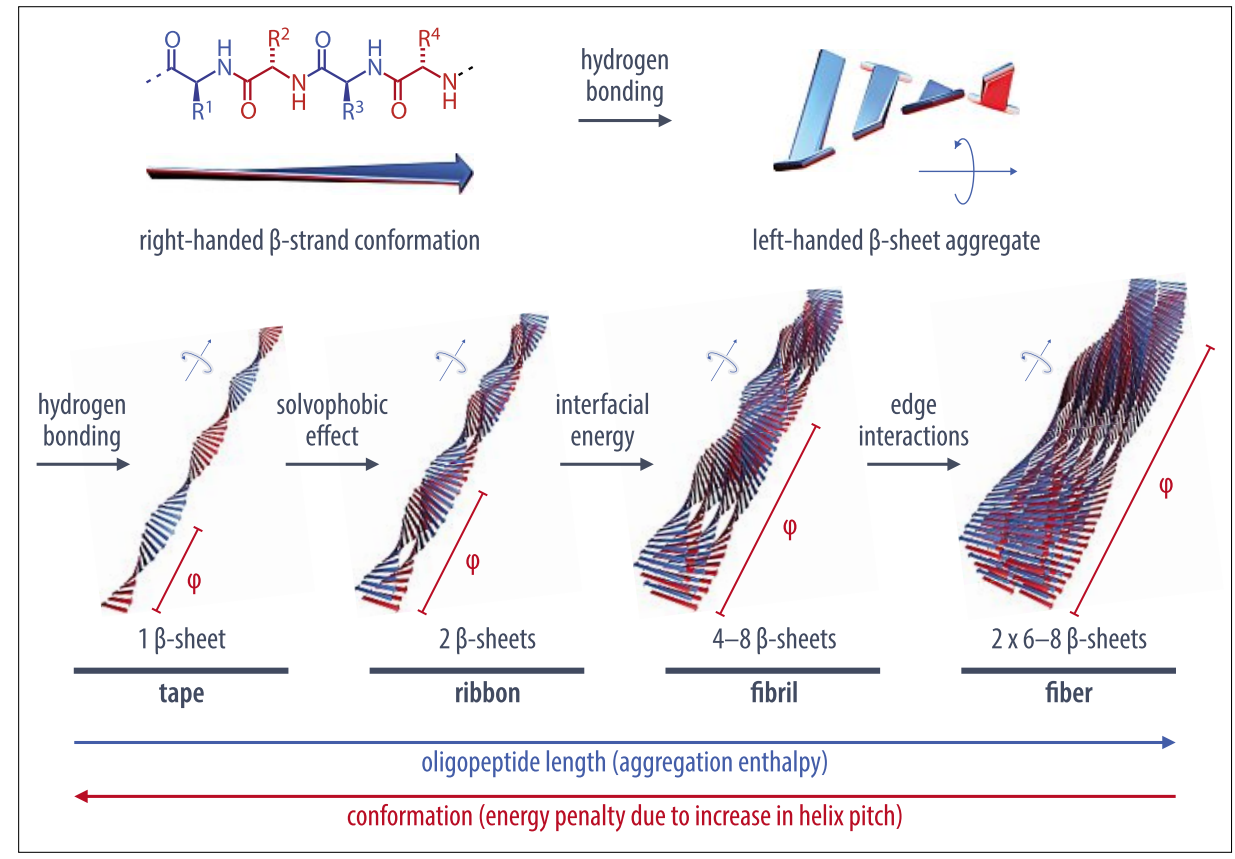

Fig. 2. Top: Conformation of an oligopeptide $\beta$-strand and the resulting $\beta$-sheet with an alternating sequence of hydrophilic (blue) and hydrophobic (red) amino acid residues. Bottom: Schematic model for the hierarchical self-organization of the latter $\beta$-sheet-forming, amphiphilic oligopeptides into tapes ( $1 \beta$-sheet), ribbons ( $2 \beta$-sheets), fibrils (4-8 $\beta$-sheets), or fibers (two times 6 -8 $\beta$-sheets).

tures bears certain similarities to the class of fibrous protein deposits referred to as amyloids. Amyloid proteins form fibrillar deposits that are in one way or another associated with diseases such as Alzheimer's, Parkinson's, and Huntington's disease, prion diseases, and type II diabetes. ${ }^{[43-47]}$ The molecular mechanisms of amyloid fiber formation has been extensively investigated as it has been shown that inhibition or prevention of fibril growth offers a therapeutic means to combat many amyloidoses. ${ }^{[48]}$ It has been shown that the resulting fibrils have very similar architecture at the nanoscopic scale and all consist of 'cross- $\beta$-sheet' structures, with individual $\beta$-strands aligned perpendicular to the fibril axis. ${ }^{[43,49,50]}$ The helically twisted filaments typically have a length of sev- eral micrometers and a uniform width of below $10 \mathrm{~nm}$; they exhibit a cross- $\beta$-sheet signature in X-ray diffractograms, with a sharp $4.7 \AA$ meridional reflection and a broader equatorial reflection at a spacing of typically $6-12 \AA$, suggesting that they comprise a finite number of 'laminated' $\beta$-sheet tapes.

From a chemistry perspective, the extensive investigations on amyloid proteins offers a highly educative example to better understand how to control the aggregation into well-defined nanofibrils. Considerable research activities have been directed towards the preparation of short peptidomimetics aimed at mimicking and understanding the corresponding self-assembly processes inspired by amyloid fibers. ${ }^{[51,52]}$ In particular, Boden et al. contributed to 


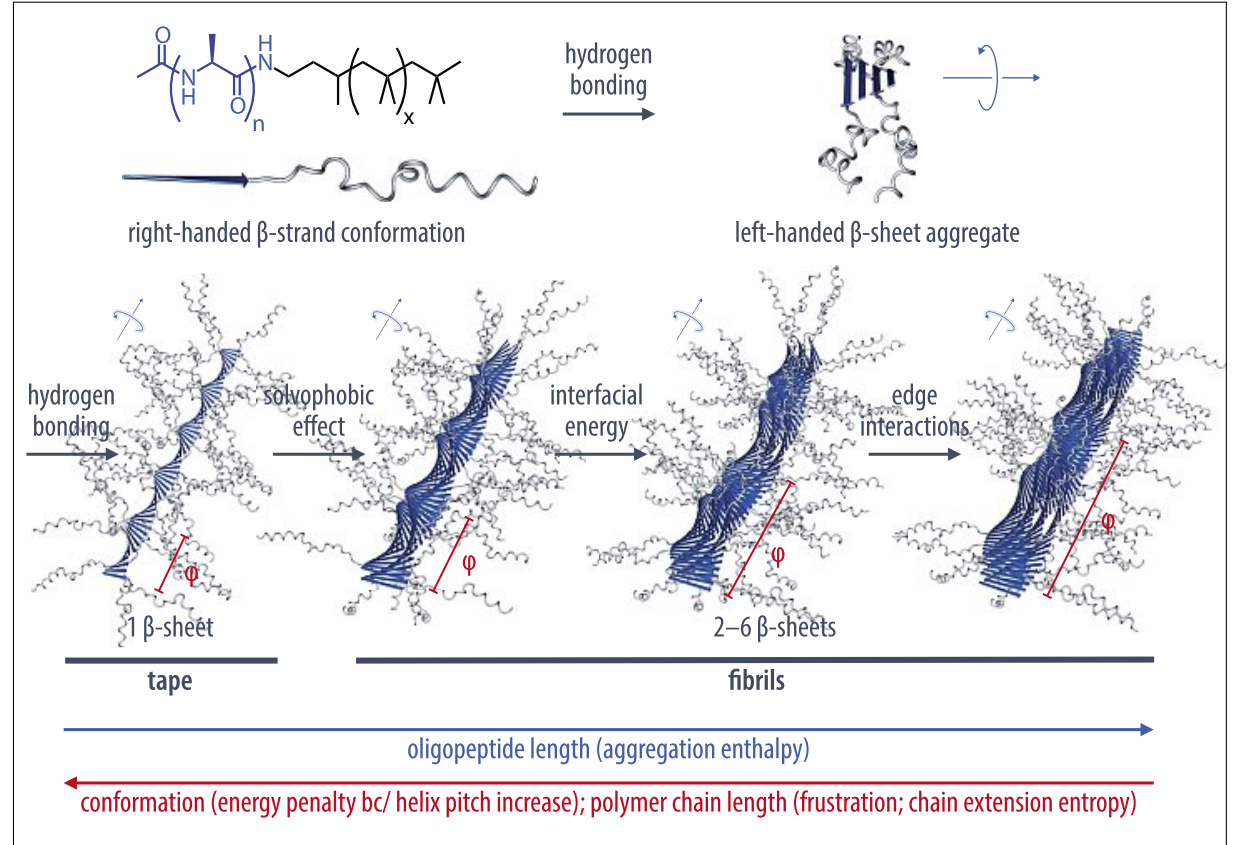

Fig. 3. Top: Schematic illustration of a non-amphiphilic oligopeptide with a terminally attached polymer. Bottom: Model for the hierarchical self-organization of the $\beta$-sheet-forming, non-amphiphilic oligopeptide-polymer derivative into tapes (1 $\beta$-sheet) and fibrils (2-6 $\beta$-sheets).

the understanding of the self-organization of short, linear oligopeptides that could form tape-like objects exhibiting a width of about 6 to $8 \mathrm{~nm}$, in agreement with the extended length of one molecule. ${ }^{[53-55]}$ Based on their results, the authors proposed a general model for the self-organization of $\beta$-sheet-forming synthetic oligopeptides into single $\beta$-sheet tapes, helically twisted ribbons, fibrils (stacked ribbons), and fibers (bundles of fibrils) (Fig. 2). An important implication of this model is the presence of an inherent helical twisting of $\beta$-sheet-based aggregates on all levels of self-organization. This is the main factor responsible for the formation of uniform one-dimensional aggregates, which are constituted of a defined, finite number of laminated $\beta$-sheet tapes. Thus, increasing the length of the $\beta$-strands or, likewise, increasing the number of stacked $\beta$-sheet tapes must inevitably result in an unwinding of the helices and a decrease of their helical twist. This is, in both cases, associated with an elastic energy penalty because the molecular conformation of the $\beta$-strands has to be adapted will, hence, deviate from the energetically most favorable conformation. Therefore, there will be an ideal equilibrium structure with a defined number of stacked $\beta$-sheet tapes and given helix pitch for a given amino acid sequence. Moreover, both the $\beta$-strand length and number of stacked $\beta$-sheet tapes are limited. This is the reason why fibrillar aggregates of more than 10 amino acid residues in width and 6-8 stacked $\beta$-sheet tapes are rarely observed, and longer oligopeptides are rather folded back via $\beta$-turns, giving structure yielded quadruple-helical poly(diacetylene)s. associated with the dense packing of the attached polymer segments. The attachment of synthetic polymer chains significantly enlarged the scope of the self-assembly of oligopeptide derivatives, which is often performed in water, and makes the selfassembly of the oligopeptide-polymer derivatives in apolar solvents possible. [56-59] Similar to the model of Boden et al., the interplay of aggregation enthalpy, disfavorable helix unwinding, and the chain extension entropy of the polymer segments will establish one well-defined thermodynamic minimum structure for any given molecular structure of an oligopeptidepolymer derivative. Whereas many groups have made important contributions to the field, the following sections will focus on those examples, where nanostrucutres of oligopeptides and oligopeptide-polymer conjugates have been employed as supramolecular scaffolds in polymer and materials science.

\section{Towards Multiple-Helical $\pi$-Conjugated Polymers}

rise to the typical cross- $\beta$-sheet structures.

Since the self-assembly of short, linear oligopeptides into $\beta$-sheets and higher structures often results in insoluble large bundles due to the edge-to-edge interactions, short polymers have been attached to the end of the oligopeptide segments (Fig. 3). The self-organization of oligopeptide-polymer derivatives is more straightforward to assess because fiber formation by edge-to-edge interactions is prohibited, and the stacking of $\beta$-sheet tapes is additionally controlled by 'frustration', that is, the unfavorable chain extension entropy
One such application is, for instance, the preparation of multiple-helical $\pi$-conjugated polymers by the topochemical polymerization of diacetylene macromonomers. ${ }^{[59-66]}$ Thus, oligopeptideequipped diacetylene macromonomers aggregated into well-defined fibrillar structures, composed of parallel $\beta$-sheets (Fig. 4). Nanofibrils with lengths of several micrometers, diameters of about 5-6 nm, and different types of helical superstructures tion (double-helical ribbon or quadruplehelical fibril) was rationalized to result were observed. The superstructure forma-

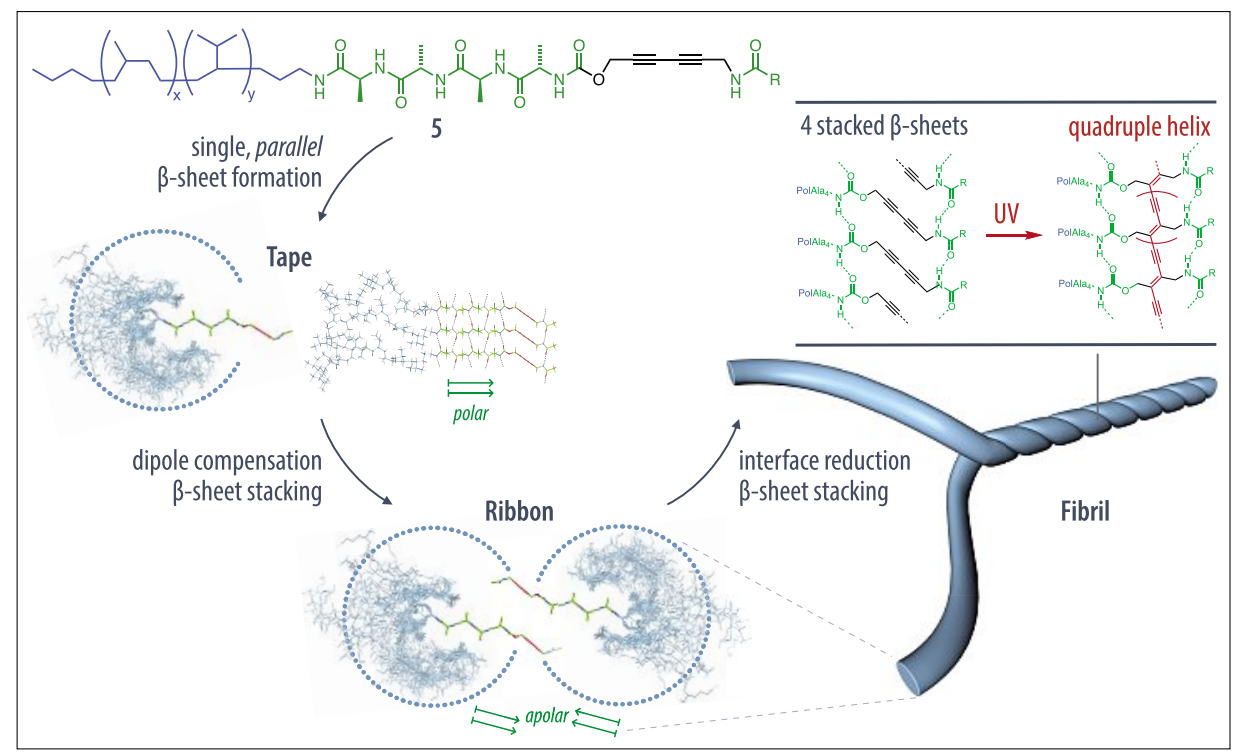

Fig. 4. Proposed model for the hierarchical self-organization of $\mathbf{5}$ into single $\beta$-sheet tapes, double-helically twisted ribbons, and quadruple-helical fibrils. UV-induced polymerization in the latter 
from a simple set of parameters such as the non-equidistant placement and the total number of $\mathrm{N}-\mathrm{H} \cdots \mathrm{O}=\mathrm{C}$ hydrogen-bonding sites in the diacetylene derivatives. The UV-induced topochemical diacetylene polymerization then, accordingly, resulted in the formation of multiple-helical polydiacetylenes. ${ }^{[59-65]}$ The latter could be unentwined by the addition of trifluoroacetic acid as a hydrogen-bond-breaking agent, resulting in two successive solvatochromic transitions associated with a helix-helix and a (reversible) helix-coil transition. ${ }^{[64]}$

\section{Towards Well-Defined Organic Nanowires}

One-dimensional nanostructures of organic semiconductors ${ }^{[67-69]}$ are not only important components for their use as defined charge percolation pathways in nanoelectronic devices, such as photovoltaic devices, ${ }^{[70-72]}$ field effect transistors (FET), ${ }^{[73-75]}$ or sensing devices, ${ }^{[76-81]}$ but they also appear to be perfect model systems for fundamental investigations of charge generation and transport in organic semiconductors under nanoscopic confinement. [82-84] Whereas 'top-down' methods such as templated growth, ${ }^{[85-88]}$ electrospinning, ${ }^{[89-95]}$ or nanolithography ${ }^{[96-98]}$ have frequently been used to obtain organic nanowires, 'bottom-up' approaches such as anisotropic crystallization [99-107] or solution-phase supramolecular selfassembly[108-111] have become increasingly popular. In this regard, oligopeptides may serve as the supramolecular scaffold to guide the one-dimensional aggregation of the $\pi$-conjugated segments. A variety of different $\pi$-conjugated molecules, such as oligothiophenes, ${ }^{1112-120]}$ naphthalenes, ${ }^{[121]}$ anthracenes, ${ }^{[122]}$ porphyrins, ${ }^{[123]}$ phenylene vinylenes, ${ }^{[124]}$ as well as perylene diimides ${ }^{[125]}$ have been combined with oligopeptides to produce 1D semiconducting nanostructures. Meijer et al. demonstrated that oligo(pheneylene vinylene) derivatives equipped with $\beta$-sheet-forming GAGAG oligopeptides formed aggregates in different solvents. ${ }^{[124]}$ Bäuerle et al. synthesized oligothiophenes equipped with oligopeptide-PEO segments that self-assembled into well-defined left-handed helical nanofibrils with lengths of up to $2 \mu \mathrm{m}$, widths of $8 \mathrm{~nm}$, and heights of $3 \mathrm{~nm} \cdot{ }^{[112-116]}$ Tovar et al. used oligopeptides inspired by the amyloid assembly paradigm to selfassemble oligothiophenes into one-dimensional nanostructures in aqueous media and used shear forces during injecting the quaterthiophene-oligopeptide hydrogels into a salt solution to produce macroscopically aligned fibrils of the oligothiophene derivatives. ${ }^{[117-119]}$ The authors performed electric transport measurements on the ob-

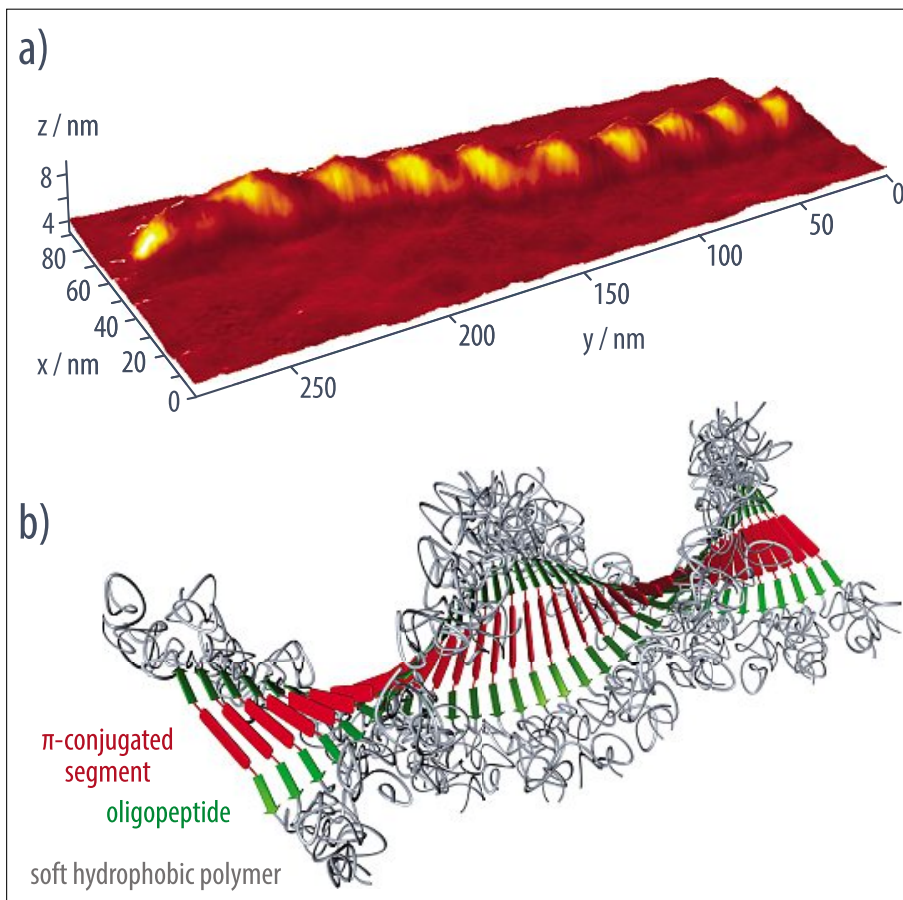

Fig. 5. AFM image and a schematic illustration of the $\pi$-conjugated molecules organized into helical onedimensional nanowires by their terminal oligopeptide-polymer substituents.

tained films and claimed hole mobilities of up to $0.03 \mathrm{~cm}^{2} \mathrm{~V}^{-1} \mathrm{~s}^{-1}$.

In an attempt to develop the use of $\beta$-sheet-forming oligopeptide-polymer substituents into a reliable supramolecular method for the formation of organic semiconducting nanofibrils with a high degree of internal order and a precise control of the nanoscopic morphology, the Frauenrath group found that their self-assembly was strictly controlled by the length of the oligopeptide segment as well as the attached flexible polymer.[66] This was then applied to the self-assembly of oligothiophene and perylene bisimide nanowires with a high degree of internal order. ${ }^{[126]}$

\section{Towards Hierarchically Structured Elastomers}

Whereas most investigations on oligopeptide-modified polymers have focused on their self-assembly into nanostructures itself, only few reports on the resulting mechanical properties of bulk materials have so far been published. Sogah et al. investigated the mechanical properties of multiblock copolymers of PEG segments and short linear or preorganized oligopeptides inspired by silk materials. ${ }^{[127-130]}$ The authors reported that the polymers self-assembled into antiparallel $\beta$-sheet structures, and the observed mechanical properties were similar to the ones obtained from films of regenerated spider silk. ${ }^{[42,131]}$ While the latter does not have properties comparable to naturally processed silk materials, this is still a remarkable achievement, given the simple nature of the building blocks. Apparently, a synthetic polymer with properties and function close to a natural biopolymer can be obtained, if only certain segments of the biopolymer are replaced by non-native ones, while keeping intact others known to be critical for the properties of the native biopolymer. Börner et al. prepared nanofibrils of poly(butyl acrylate)-oligopeptide derivatives and dispersed them in high molecular weight poly(butyl acrylate). AFM imaging showed that nanofibrils were well-dispersed in the polymer matrix. By the observed increase in storage and loss moduli in shear rheology measurements of the blends, the authors proved that the oligopeptide-polymer conjugate acted as a molecular reinforcement. [132]

Since $\beta$-sheet-forming oligopeptides are ditopic, multivalent, and self-complementary hydrogen-bonded ligands, the structures obtained from their aggregates may also be regarded as specific examples of supramolecular polymers.[133,134] By analogy, aggregation of the corresponding oligopeptide-modified synthetic polymers will yield supramolecular graft copolymers, and difunctional oligopeptide-polymer derivatives will give rise to supramolecular networks.

\section{Conclusions}

In conclusion, oligopeptide-modified polymer derivatives are reliable supramolecular synthons for the formation of defined supramolecular assemblies that exhibit hierarchical structure formation. They can be regarded as a versatile toolbox towards the novel supramolecular 
materials. The well-investigated formation of one-dimensional nanostructures can be used as a supramolecular scaffold for the self-assembly of other types of molecular segments. In this way, $\pi$-conjugated molecules can, for instance, be reliably organized into organic nanowires (Fig. 5). On the other hand, bulk materials may serve as hierarchically structured polymer materials, with applications as reinforced elastomers or high performance damping materials. These examples serve to show that, by developing a detailed understanding of the self-assembly processes in nature, one can move from the simple copying or recreating biomaterials and their functions to rationalizing, simplifying, and transferring the underlying design principles to synthetic materials so that they may be combined with properties unknown in the realm of biomaterials.

\section{Acknowledgments}

Funding from the European Research Council (ERC Grant 239831, 'OrgElNanoCarbMater'), the Swiss National Science Foundation (SNF Grants 200020121812, 200021-129712, 20000_144416, 20000_144417), and ETH Zürich (ETH Research Grant TH 20 07-1) is gratefully acknowledged.

Received: July 3, 2013

[1] A. V. Srinivasan, G. K. Haritos, F. L. Hedberg, Appl. Mech. Rev. 1991, 44, 463.

[2] S. Mitragotri, J. Lahann, Nature Mater. 2009, 8,15 .

[3] M. A. Meyers, P. Y. Chen, A. Y. M. Lin, Y. Seki, Prog. Mater. Sci. 2008, 53, 1 .

[4] F. Vollrath, D. P. Knight, Nature 2001, 410, 541.

[5] C. Vepari, D. L. Kaplan, Prog. Polym. Sci. 2007, 32, 991

[6] T. A. Sikoryn, D. W. L. Hukins, J. Orthop. Res. 1990, 8, 586.

[7] L. U. Bigliani, R. G. Pollock, L. J. Soslowsky, E. L. Flatow, R. J. Pawluk, V. C. Mow, J. Orthop. Res. 1992, 10, 187.

[8] L. Han, A. J. Grodzinsky, C. Ortiz, Annu. Rev. Mater. Res. 2011, 41, 133.

[9] P. Fratzl, Curr. Opin. Colloid Interface Sci. 2003, 8, 32.

[10] R. Lakes, Nature 1993, 361, 511.

[11] M. A. Meyers, A. Y. M. Lin, Y. Seki, P. Y. Chen, B. K. Kad, S. Bodde, JOM 2006, 58, 35.

[12] S. Hecht, Mater. Today 2005, 8, 48.

[13] C. J. Hawker, K. L. Wooley, Science 2005, 309, 1200.

[14] M. Muthukumar, C. K. Ober, E. L. Thomas, Science 1997, 277, 1225.

[15] J. G. Hardy, L. M. Römer, T. R. Scheibel, Polymer 2008, 49, 4309.

[16] R. V. Lewis, Chem. Rev. 2006, 106, 3762

[17] D. Huemmerich, U. Slotta, T. Scheibel, Appl. Phys. A: Mater. Sci. Process. 2006, 82, 219.

[18] S. Schulz, Angew. Chem. Int. Ed. 1997, 36, 314.

[19] X. Chen, Z. Shao, F. Vollrath, Soft Matter 2006, 2, 448.

[20] I. Krasnov, I. Diddens, N. Hauptmann, G. Helms, M. Ogurreck, T. Seydel, S. S. Funari, M. Muller, Phys. Rev. Lett. 2008, 100, 1.

[21] T. Scheibel, Appl. Phys. A: Mater. Sci. Process. 2006, 82, 191.

[22] F. Vollrath, D. Porter, Soft Matter 2006, 2, 377.
[23] C. Dicko, J. M. Kenney, F. Vollrath, $A d v$. Protein Chem. 2006, 73, 17.

[24] M. Heim, D. Keerl, T. Scheibel, Angew. Chem. Int. Ed. 2009, 48, 3584.

[25] D. P. Knight, F. Vollrath, Philos. Trans. R. Soc. London, Ser. B 2002, 357, 155.

[26] A. E. Brooks, S. M. Stricker, S. B. Joshi, T. J. Kamerzell, C. R. Middaugh, R. V. Lewis, Biomacromolecules 2008, 9, 1506.

[27] V. L. Brookes, R. J. Young, F. J. Vollrath, Mater. Sci. 2008, 43, 3728.

[28] H. Zhou, Y. Zhang, Phys. Rev. Lett. 2005, 94, 028104.

[29] D. Porter, F. Vollrath, Z. Shao, Eur. Phys. J. E 2005, 16, 199.

[30] N. Becker, E. Oroudjev, S. Mutz, J. P. Cleveland, P. K. Hansma, C. Y. Hayashi, D. E. Makarov, H. G. Hansma, Nature Mater. 2003, 2, 278.

[31] Y. Termonia, Biomacromolecules 2004, 5, 2404.

[32] U. Slotta, S. Hess, K. Spiess, T. Stromer, L. Serpell, T. Scheibel, Macromol. Biosci. 2007, 7, 183.

[33] A. H. Simmons, C. A. Michal, L. W. Jelinski, Science 1996, 271, 84

[34] J. P. O'Brien, S. R. Fahnestock, Y. Termonia, K. H. Gardner, Adv Mater 1998, 10, 1185.

[35] I. Marcotte, J. D. van Beek, B. H. Meier, Macromolecules 2007, 40, 1995.

[36] F. Vollrath, D. Porter, Appl. Phys. A: Mater. Sci. Process. 2006, 82, 205.

[37] N. Du, Z. Yang, X. Y. Liu, Y. Li, H. Y. Xu, $A d v$. Funct. Mater. 2011, 21, 772 .

[38] T. Lefevre, M.-E. Rousseau, M. Pezolet, Biophys. J. 2007, 92, 2885.

[39] A. Nova, S. Keten, N. M. Pugno, A. Redaelli, M. J. Buehler, Nano Lett. 2010, 10, 2626.

[40] S. Keten, Z. P. Xu, B. Ihle, M. J. Buehler, Nature Mater. 2010, 9, 359.

[41] D. Porter, F. Vollrath, Adv. Mater. 2009, 21, 487.

[42] L. W. Jelinski, Curr. Opin. Solid State Mater. Sci. 1998, 3, 237.

[43] H. Frauenrath, E. Jahnke, Chem. Eur. J. 2008, 14, 2942.

[44] D. J. Selkoe, Nature 2003, 426, 900.

[45] R. Tycko, Curr. Opin. Struct. Biol. 2004, 14, 96.

[46] O. S. Makin, L. C. Serpell, FEBS J. 2005, 272, 5950.

[47] R. Nelson, D. Eisenberg, Adv. Protein Chem. 2006, 73, 235

[48] S. Connelly, S. Choi, S. M. Johnson, J. W. Kelly, I. A. Wilson, Curr. Opin. Struct. Biol. 2010, 20, 54.

[49] M. Sunde, L. C. Serpell, M. Bartlam, P. E. Fraser, M. B. Pepys, C. C. F. Blake, J. Mol. Biol. 1997, 273, 729.

[50] O. Sumner Makin, L. C. Serpell, J. Mol. Biol. 2004, 335, 1279.

[51] T. Moriuchi, T. Hirao, J. Incl. Phenom. Macro. 2012, 74, 23.

[52] S. G. Zhang, Nature Biotechnol. 2003, 21, 1171 .

[53] A. Aggeli, M. Bell, N. Boden, J. N. Keen, P. F. Knowles, T. C. McLeish, M. Pitkeathly, S. E. Radford, Nature 1997, 386, 259.

[54] A. Aggeli, M. Bell, N. Boden, J. N. Keen, T. C. B. McLeish, I. Nyrkova, S. E. Radford, A. Semenov, J. Mater. Chem. 1997, 7, 1135.

[55] A. Aggeli, N. Boden, Y.-L. Cheng, J. B. C. Findlay, P. F. Knowles, P. Kovatchev, P. J. H. Turnbull, L. Horvath, D. Marsh, Biochemistry 1996, 35, 16213.

[56] H. M. König, A. F. M. Kilbinger, Angew. Chem. Int. Ed. 2007, 46, 8334.

[57] J. Hentschel, H. G. Börner, J. Am. Chem. Soc. 2006, 128,14142

[58] J. Hentschel, M. G. J. ten Cate, H. G. Borner, Macromolecules 2007, 40, 9224.

[59] E. Jahnke, I. Lieberwirth, N. Severin, J. P.
Rabe, H. Frauenrath, Angew. Chem. Int. Ed. 2006, 45, 5383.

[60] E. Jahnke, A.-S. Millerioux, N. Severin, J. P. Rabe, H. Frauenrath, Macromol. Biosci. 2007, 7, 136.

[61] E. Jahnke, N. Severin, P. Kreutzkamp, J. P. Rabe, H. Frauenrath, Adv. Mater. 2008, 20, 409.

[62] H. Frauenrath, E. Jahnke, Chem. Eur. J. 2008, 14, 2942.

[63] J. Weiss, E. Jahnke, H. Frauenrath, Macromol. Rapid Commun. 2008, 29, 330.

[64] J. Weiss, E. Jahnke, N. Severin, J. P. Rabe, H. Frauenrath, Nano Lett. 2008, $8,1660$.

[65] E. Jahnke, J. Weiss, S. Neuhaus, T. N. Hoheisel, H. Frauenrath, Chem. Eur. J. 2009, 15, 388.

[66] L. F. Tian, R. Szilluweit, R. Marty, L. Bertschi, M. Zerson, E. C. Spitzner, R. Magerle, H. Frauenrath, Chem. Sci. 2012, 3, 1512 .

[67] E. Moulin, J. J. Cid, N. Giuseppone, $A d v$. Mater. 2013, 25, 477.

[68] F. S. Kim, G. Ren, S. A. Jenekhe, Chem. Mater. 2010, 23, 682 .

[69] M. Hasegawa, M. Iyoda, Chem. Soc. Rev. 2010, 39, 2420.

[70] H. Xin, F. S. Kim, S. A. Jenekhe, J. Am. Chem Soc. 2008, 130, 5424.

[71] A. Wicklein, S. Ghosh, M. Sommer, F Würthner, M. Thelakkat, ACS Nano 2009, 3, 1107.

[72] L. Schmidt-Mende, A. Fechtenkötter, K Müllen, E. Moons, R. H. Friend, J. D MacKenzie, Science 2001, 293, 1119.

[73] A. L. Briseno, S. C. B. Mannsfeld, S. A Jenekhe, Z. Bao, Y. Xia, Materials Today 2008, 11,38 .

[74] S. Xiao, J. Tang, T. Beetz, X. Guo, N. Tremblay, T. Siegrist, Y. Zhu, M. Steigerwald, C. Nuckolls, J. Am. Chem. Soc. 2006, 128, 10700 .

[75] J. A. Merlo, C. D. Frisbie, J. Polym. Sci., Part B: Polym. Phys. 2003, 41, 2674.

[76] Y. Che, D. E. Gross, H. Huang, D. Yang, X. Yang, E. Discekici, Z. Xue, H. Zhao, J. S. Moore, L. Zang, J. Am. Chem. Soc. 2012, 134, 4978.

[77] H. Liu, J. Kameoka, D. A. Czaplewski, H. G. Craighead, Nano Lett. 2004, 4, 671.

[78] Y. S. Zhao, J. S. Wu, J. X. Huang, J. Am. Chem. Soc. 2009, 131, 3158.

[79] S. Virji, J. X. Huang, R. B. Kaner, B. H. Weiller, Nano Lett. 2004, 4, 491.

[80] Y. Che, X. Yang, S. Loser, L. Zang, Nano Lett. 2008, 8, 2219.

[81] G. A. O'Brien, A. J. Quinn, D. A. Tanner, G. Redmond, Adv. Mater. 2006, 18, 2379.

[82] A. N. Aleshin, Adv. Mater. 2006, 18, 17.

[83] F. C. Grozema, L. D. A. Siebbeles, Int. Rev. Phys. Chem. 2008, 27, 87.

[84] W. Pisula, X. L. Feng, K. Mullen, Chem. Mater. 2011, 23, 554.

[85] J. C. Hulteen, C. R. Martin, J. Mater. Chem. 1997, 7, 1075

[86] J. I. Lee, S. H. Cho, S.-M. Park, J. K. Kim, J. K. Kim, J.-W. Yu, Y. C. Kim, T. P. Russell, Nano Lett. 2008, 8, 2315.

[87] X. Zhang, J. Zhang, Z. Liu, C. Robinson, Chem. Commun. 2004, 1852 .

[88] H. Yoon, M. Chang, J. Jang, Adv. Funct. Mater. 2007, 17, 431.

[89] A. Frenot, I. S. Chronakis, Curr. Opin. Colloid Interface Sci. $2003,8,64$.

[90] D. H. Reneker, I. Chun, Nanotechnology 1996, 7, 216.

[91] A. Greiner, J. H. Wendorff, Angew. Chem. Int. Ed. 2007, 46, 5670.

[92] D. Li, Y. N. Xia, Adv. Mater. 2004, 16, 1151.

[93] J. Y. Chen, C. C. Kuo, C. S. Lai, W. C. Chen, H. L. Chen, Macromolecules 2011, 44, 2883

[94] S. W. Lee, H. J. Lee, J. H. Choi,W. G. Koh, J. M. Myoung, J. H. Hur, J. J. Park, J. H. Cho, U. Jeong, Nano Lett. 2009, 10, 347. 
[95] C. C. Kuo, C. T. Wang, W. C. Chen, Macromol. Mater. Eng. 2008, 293, 999.

[96] J. H. Lim, C. A. Mirkin, Adv. Mater. 2002, 14, 1474.

[97] W. S. Beh, I. T. Kim, D. Qin, Y. Xia, G. M. Whitesides, Adv. Mater. 1999, 11, 1038.

[98] A. Noy, A. E. Miller, J. E. Klare, B. L. Weeks, B. W. Woods, J. J. DeYoreo, Nano Lett. 2001 2, 109.

[99] R. Li, W. Hu, Y. Liu, D. Zhu, Acc. Chem. Res. 2010, 43, 529.

[100] R. W. I. de Boer, M. E. Gershenson, A. F Morpurgo, V. Podzorov, Phys. Status Solidi A 2004, 201, 1302.

[101] C. Reese, Z. Bao, Mater. Today 2007, 10, 20.

[102] A. L. Briseno, S. C. B. Mannsfeld, X. Lu, Y. Xiong, S. A. Jenekhe, Z. Bao, Y. Xia, Nano Lett. 2007, 7, 668.

[103] Y. B. Song, C. A. Di, X. D. Yang, S. P. Li, W Xu, Y. Q. Liu, L. M. Yang, Z. G. Shuai, D. Q. Zhang, D. B. Zhu, J. Am. Chem. Soc. 2006, $128,15940$.

[104] R. Li, H. Li, Y. Song, Q. Tang, Y. Liu, W. Xu, W. Hu, D. Zhu, Adv. Mater. 2009, 21, 1605.

[105] D. H. Kim, D. Y. Lee, H. S. Lee, W. H. Lee, Y H. Kim, J. I. Han, K. Cho, Adv. Mater. 2007, $19,678$.

[106] A. D. Schwab, D. E. Smith, B. Bond-Watts, D E. Johnston, J. Hone, A. T. Johnson, J. C. de Paula, W. F. Smith, Nano Lett. 2004, 4, 1261.

[107] Y. Sun, L. Tan, S. Jiang, H. Qian, Z. Wang, D. Yan, C. Di, Y. Wang, W. Wu, G. Yu, S. Yan, C. Wang, W. Hu, Y. Liu, D. Zhu, J. Am. Chem. Soc. 2007, 129, 1882.

[108] V. Faramarzi, F. Niess, E. Moulin, M. Maaloum, J. F. Dayen, J. B. Beaufrand, S. Zanettini, B. Doudin, N. Giuseppone, Nature Chem. 2012, 4, 485 .
[109] C. C. Lee, C. Grenier, E. W. Meijer, A. P. H. Schenning, J. Chem. Soc. Rev. 2009, 38, 671.

[110] S. H. Kim, J. R. Parquette, Nanoscale 2012, 4, 6940.

[111] Y. Yamamoto, T. Fukushima, Y. Suna, N. Ishii, A. Saeki, S. Seki, S. Tagawa, M. Taniguchi, T. Kawai, T. Aida, Science 2006, 314, 1761.

[112] H.-A. Klok, A. Rösler, G. Götz, E. MenaOsteritz, P. Bäuerle, Org. Biomol. Chem. 2004, 2, 3541 .

[113] E.-K. Schillinger, E. Mena-Osteritz, J. Hentschel, H. G. Boerner, P. Baeuerle, Adv. Mater. 2009, 21, 1562.

[114] J. Cremer, E. Mena-Osteritz, N. G. Pschierer, K. Müllen, P. Baeuerle, Org. Biomol. Chem. 2005, 3, 985 .

[115] A. K. Shaytan, E. K. Schillinger, E. MenaOsteritz, S. Schmid, P. G. Khalatur, P. Bauerle, A. R. Khokhlov, Beilstein J. Nanotech. 2011 , 2, 525 .

[116] A. K. Shaytan, E. K. Schillinger, P. G. Khalatur, E. Mena-Osteritz, J. Hentschel, H. G. Borner, P. Bauerle, A. R. Khokhlov, ACS Nano 2011, 5 , 6894

[117] G. S. Vadehra, B. D. Wall, S. R. Diegelmann, J. D. Tovar, Chem. Commun. 2010, 46, 3947.

[118] S. R. Diegelmann, J. M. Gorham, J. D. Tovar, J. Am. Chem. Soc. 2008, 130, 13840.

[119] B. D. Wall, S. R. Diegelmann, S. Zhang, T. J. Dawidczyk, W. L. Wilson, H. E. Katz, H.-Q. Mao, J. D. Tovar, Adv. Mater. 2011, 23, 5009.

[120] D. A. Stone, L. Hsu, S. I. Stupp, Soft Matter 2009, 5, 1990.

[121] H. Shao, T. Nguyen, N. C. Romano, D. A. Modarelli, J. R. Parquette, J. Am. Chem. Soc. 2009, 131, 16374.
[122] Y. Sun, L. Jiang, K. C. Schuermann, W. Adriaens, L. Zhang, F. Y. C. Boey, L. De Cola, L. Brunsveld, X. Chen, Chem. Eur. J. 2011, 17, 4746.

[123] Q. B. Wang, Y. L. Chen, P. Ma, J. T. Lu, X. M. Zhang, J. Z. Jiang, J. Mater. Chem. 2011, 21, 8057.

[124] R. Matmour, I. De Cat, S. J. George, W. Adriaens, P. Leclère, P. H. H. Bomans, N. A. J. M. Sommerdijk, J. C. Gielen, P. C. M. Christianen, J. T. Heldens, J. C. M. van Hest, D. W. P. M. Löwik, S. De Feyter, E. W. Meijer, A. P. H. J. Schenning, J. Am. Chem. Soc. 2008, 130, 14576.

[125] Y. Tidhar, H. Weissman, S. G. Wolf, A. Gulino, B. Rybtchinski, Chem. Eur. J. 2011, 17, 6068.

[126] R. Marty, R. Szilluweit, L. Tian, A. SánchezFerrer, S. Bolisetty, J. Adamcik, R. Mezzenga, E.-C. Spitzner, M. Feifer, R. Magerle, S. Steinmann, C. Corminboeuf, H. Frauenrath, 2013, submitted.

[127] M. J. Winningham, D. Y. Sogah, Macromolecules 1997, 30, 862

[128] O. Rathore, D. Y. Sogah, Macromolecules 2001, 34, 1477.

[129] O. Rathore, D. Y. Sogah, J. Am. Chem. Soc. 2001, 123, 5231.

[130] O. Rathore, M. J. Winningham, D. Y. Sogah, J. Polym. Sci., Part A: Polym. Chem. 2000, 38, 352.

[131] M. B. Hinman, J. A. Jones, R. V. Lewis, Trends Biotechnol. 2000, 18, 374

[132] J. Hentschel, H. G. Boerner, Macromol. Biosci. 2009, 9, 187.

[133] T. Aida, E. W. Meijer, S. I. Stupp, Science 2012, 335, 813

[134] L. Bouteiller, Adv. Polym. Sci. 2007, 207, 79. 